\title{
ASSESSMENT THE PERFORMANCE OF THE TRIANGULAR INTEGRATED COLLECTOR
}

\author{
Omer Khalil Ahmed
}

Dept. of the refrigeration and air- conditioning, Technical college/Kirkuk - Northern technical university Kirkuk, Iraq - (omerkalil@yahoo.com)

Received: Jul. 2018 / Accepted: Dec., 2018 / Published: Dec., 2018 https://doi.org/10.25271/sjuoz.2018.6.4.542

\begin{abstract}
:
A numerical study was achieved on a new design of storage solar collector. The storage collector is a triangular face and a right triangular pyramid for the volumetric shape. It is obtained by cutting a cube from one upper corner at $45^{\circ}$, down to the opposite hypotenuse of the base of the cube. The numerical study was carried out using the computational fluid dynamics code (ANSYSFluent) software with natural convection phenomenon in the pyramid enclosure. The results show that, the temperature and velocity distributions throughout the operating period were obtained. The influence of introducing an internal partition inside the triangular storage collector was investigated. Also the optimum geometry and location for this partition were obtained. The enhancement was best at $y=0.25 \mathrm{~m}$ whereas the height of triangular collector was $0.5 \mathrm{~m}$. The hourly system performance was evaluated for all test conditions.
\end{abstract}

KEYWORDS: Triangular, storage, solar, collector, assessment, performance.

\section{INTRODUCTION}

The cost of manufacturing solar collectors is $200 \$$ per square meter (Adeyanju, 2013; Ahmed \& Ahmed, 2011; Khalil \& Aziz, 2017). This high initial cost is the first problem preventing solar collector to become popular for the human. It is the intent of this study to develop a low cost, reliable, and efficient solar water heater system for domestic use (Ahmed \& Mohammed, 2017). All the classical solar water heater systems contain two main components; the collector and the storage tank. Joudi (1990), suggested a new storage solar collector for domestic hot water supply and the collector was fabricated easily from the commonly available commercial materials using simple tools and procedures. The advantage of the suggested collector design is that it can be used for water storage to replace the ordinary cubical or cylindrical water tank commonly used in Iraqi houses. Ahmed (2018), analyzed analytically and experimentally the design of a compact solar collector. In the suggested design the collector and the water tank are compact into one part with water flow caused by thermsyphonic action. The performance of a new model of the storage solar collector was investigated numerically by Farhan (Joudi, 2004). The ANSYS software was utilized for this assessment. Also, Ahmed, (2017) studied numerically and experimentally the performance of a cylindrical compact collector in Kirkuk city. The invention includes an engineering design fabricated by cutting a cubic tank at different orientations. In this design, the ideal angle of inclination is $10^{\circ}$ to $15^{\circ}$ more than the latitude angle to collect the solar energy in the winter season. The latitude angle for Basra is $31^{\circ}$, Baghdad is $33^{\circ}$ and Mosul is $36^{\circ}$. Accordingly, for ease and unity, a $45^{\circ}$ common angle of inclination would be suitable (Ahmed \& Bawa, 2018). The volume of the collector can be controlled using different dimensions for the base and height simultaneously. To increase the absorption of solar energy, the sunlit surface has been painted black. The sunlit surface is painted black to increase solar energy absorption. A glass sheet or any other transparent materials can be used to cover the tilted side that is facing the sun and all the other sides can be insulated using thermal insulation (Ahmed \& Bawa, 2018).
The present work was carried out to study numerically, in three dimensions, the effect of the some operational parameters on the performance of the triangular storage collector shown in Fig.(1).

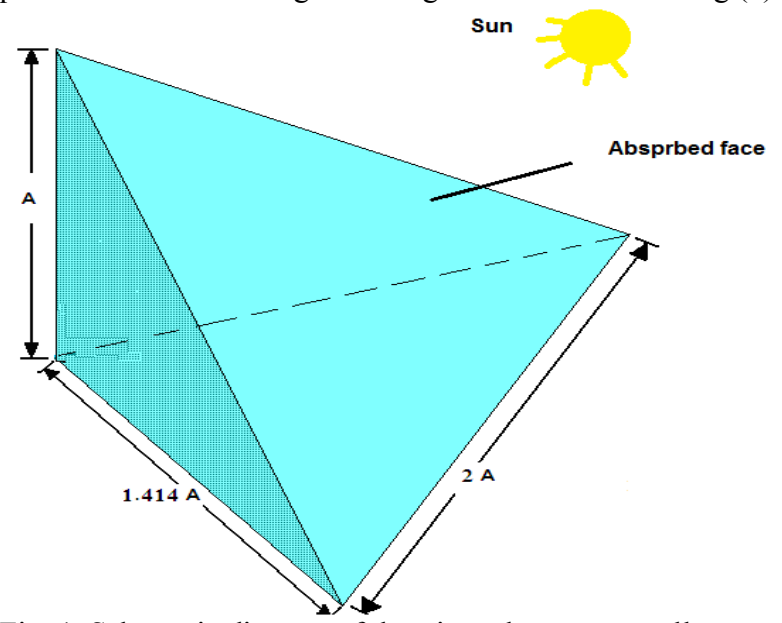

Fig. 1. Schematic diagram of the triangular storage collector

\section{NUMERICAL MODEL}

The Boussinesq approximation, wherein the fluid is assumed to be Newtonian and incompressible, means that the fluid density is taken as constant except for the effect of the density variation in producing buoyant forces. The density is assumed to vary only with temperature slightly from a reference value (Al-Nimr et al., 2018). With these assumptions the buoyant effects, characteristic of free convection, are included as body forces in the momentum equations. The fluid motion is assumed to be laminar because of very low velocity within the storage, three dimensional, no internal heat generation and for convenience the effects of radiation and viscous energy dissipation are neglected. With these assumptions, the basic convection equations are (H. K. V. \& W. Malalasekera, 2007):

1- Continuity Equation:

$$
\frac{\partial u}{\partial t}+\frac{\partial u}{\partial x}+\frac{\partial v}{\partial y}+\frac{\partial w}{\partial z}=0
$$


2- Momentum equations:

$\frac{\partial u}{\partial t}+u \frac{\partial u}{\partial x}+v \frac{\partial u}{\partial y}+w \frac{\partial u}{\partial z}=-\frac{1}{\rho} \frac{\partial p}{\partial x}+v\left[\frac{\partial^{2} u}{\partial x^{2}}+\frac{\partial^{2} u}{\partial y^{2}}+\frac{\partial^{2} u}{\partial z^{2}}\right]$ $\frac{\partial v}{\partial t}+u \frac{\partial v}{\partial x}+v \frac{\partial v}{\partial y}+w \frac{\partial v}{\partial z}=-\frac{1}{\rho} \frac{\partial p}{\partial y}+g \beta\left(T-T_{o}\right)+$

$v\left[\frac{\partial^{2} v}{\partial x^{2}}+\frac{\partial^{2} v}{\partial y^{2}}+\frac{\partial^{2} v}{\partial z^{2}}\right]$

$\frac{\partial w}{\partial t}+u \frac{\partial w}{\partial x}+v \frac{\partial w}{\partial y}+w \frac{\partial w}{\partial z}=-\frac{1}{\rho} \frac{\partial p}{\partial z}+v\left[\frac{\partial^{2} w}{\partial x^{2}}+\frac{\partial^{2} w}{\partial y^{2}}+\frac{\partial^{2} w}{\partial z^{2}}\right]$

3- Energy equation:

$\frac{\partial T}{\partial t}+u \frac{\partial T}{\partial x}+v \frac{\partial T}{\partial y}+w \frac{\partial T}{\partial z}=\frac{K}{\rho^{*} C_{p}}\left[\frac{\partial^{2} T}{\partial x^{2}}+\frac{\partial^{2} T}{\partial y^{2}}+\frac{\partial^{2} T}{\partial z^{2}}\right]$

In the finite volume method, the above equations are treated in a balanced form for finite-sized control volumes (CV). Equations 1, 2, and 3 can be re-written as[12]:

$$
\begin{aligned}
& \frac{\partial(\rho \phi)}{\partial t}+\frac{\partial(\rho u \phi)}{\partial x}+\frac{\partial(\rho v \phi)}{\partial y}+\frac{\partial(\rho w \phi)}{\partial z}= \\
& \frac{\partial}{\partial x}\left(\Gamma \frac{\partial \phi}{\partial x}\right)+\frac{\partial}{\partial y}\left(\Gamma \frac{\partial \phi}{\partial y}\right)+\frac{\partial}{\partial z}\left(\Gamma \frac{\partial \phi}{\partial z}\right)+S
\end{aligned}
$$

The fully implicit discretization equation for a typical control volume is shown as follows:

$$
\begin{aligned}
& a_{P} \phi_{P}=a_{W} \phi_{W}+a_{E} \phi_{E}+a_{S} \phi_{S}+a_{N} \phi_{N} \\
& +a_{B} \phi_{B}+a_{T} \phi_{T}+a_{P}^{0} \phi_{P}^{0}+S_{u}
\end{aligned}
$$

Re-write the above equations in the following terms:

$$
\frac{\partial(\rho \phi)}{\partial t}+\operatorname{div}(\rho \phi u)=\operatorname{div}(\Gamma \operatorname{grad}(\phi))+S
$$

The storage solar collector complex geometry requires computational fluid dynamics approach. Standard correlations of heat transfer cannot adequately describe the natural convection within the solar storage collector (Al-Nimr et al., 2018). A commercial package of CFD (Fluent) was used to model the collector in this study with the utilization of Gambit software for mesh generation. The triangular collector grid was built as in Figure (2). In this model, tetrahedral element type was chosen using a segregated solver with the implicit formulation. The second order scheme was used to solve the momentum and energy equations (Rahman, 2011). Buoyancy-driven flow is known as natural convection flow and the Boussinesq approximation is used for density. The discretization of the body force weighted scheme is recommended to solve high Rayleigh number flows. Accordingly, the body force weighted scheme was implemented to discretize the pressure term (ANSYS, 2013). Pressure-implicit with the splitting of operators (PISO) algorithm, which is recommended for transient flow calculation, was used to achieve the pressure-velocity coupling. In order to control the variable fluctuations and avoid divergence of solutions during successive iterations, under-relaxation factors were applied. When solving the equations, the typical underrelaxation parameter values used were approximately 0.3 and 0.7 for pressure and momentum, respectively, and 0.8 for both energy and density (Mohammed, 2018).

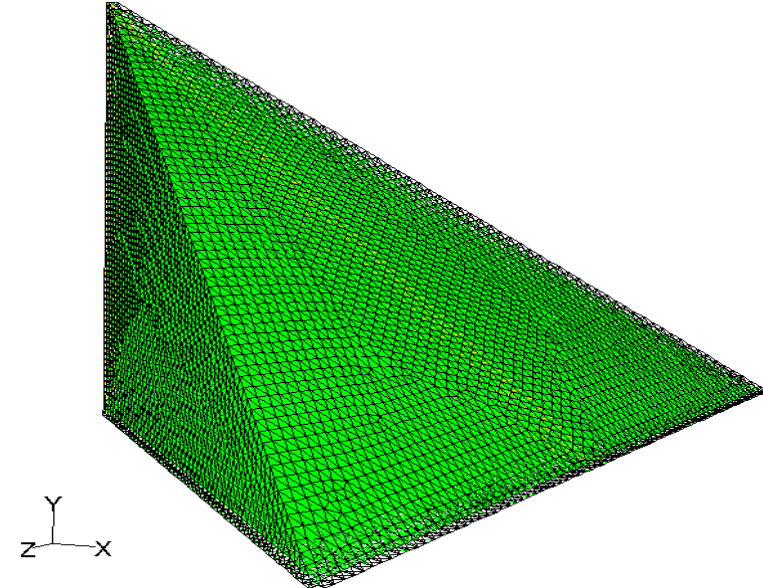

Fig. 2. Mesh model of the triangular collector

\section{RESULTS AND DISCUSSIONS}

The hourly incident solar radiation on a titled surface for 365 days was obtained by a computer program developed in this work based on the ASHRAE clear sky model (H. K. V. \& W. Malalasekera, 2007; Shukla, et al., 2013). The volume of the triangular collector is 41.667 liters and the sunlit area is 0.353 $\mathrm{m} 2$ at a height (A) of $0.5 \mathrm{~m}$. All results were evaluated for a typical winter days (13th, 14th, 15th and 16th of November). The hourly incident solar radiation on a titled surface for 365 days was obtained by a computer program developed in this work based on the ASHRAE clear sky model (Ben Slama, 2013). The volume of the triangular collector is 41.667 liters and the sunlit area is $0.353 \mathrm{~m}^{2}$ at a height (A) of $0.5 \mathrm{~m}$. All results were evaluated for a typical winter days $\left(13^{\text {th }}, 14^{\text {th }}, 15^{\text {th }}\right.$ and $16^{\text {th }}$ of November).

\subsection{Effect of Collector Volume}

Fig. (3) shows the relation between the mean storage temperature and the heights of the collector. A varying height and base dimensions renders varying storage volumes. It is observed that the mean storage temperature decreased with increasing volume (Chaabane et al., 2014). It is observed that the mean storage temperature reaches its maximum value at $\mathrm{A}=0.5 \mathrm{~m}$, where the collector volume is 41.67 literss. The minimum is obtained for a collector with $A=1 \mathrm{~m}$, where the collector volume is 333.33 liters. Also, the results predictions show that the stratified behavior of the collector becomes weaker with increasing volume, as shown in Fig. (4).

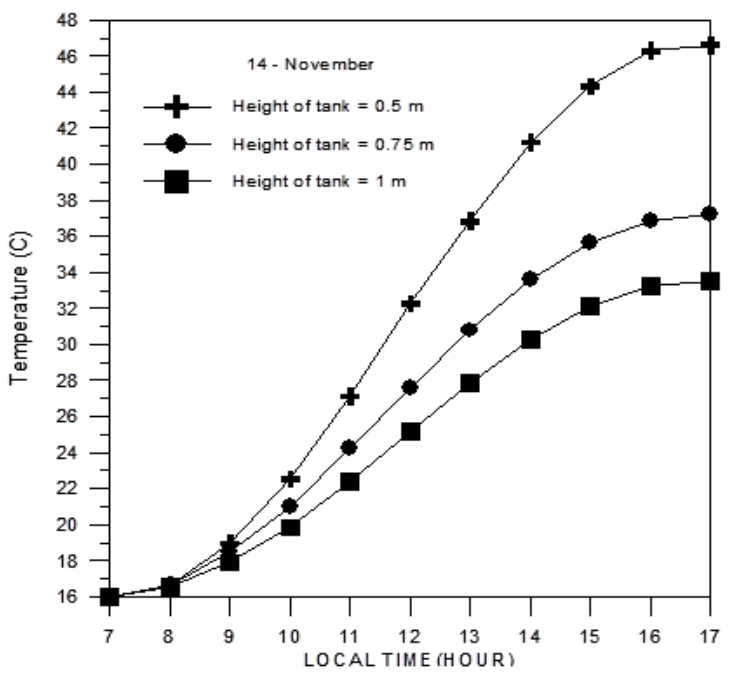

Fig. 3. Variation of mean storage temperature for various volumes 


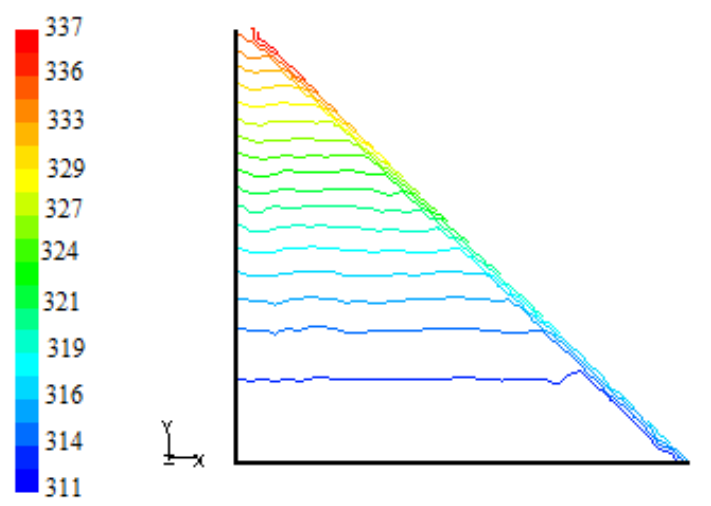

(a) Isothermal temperature lines at symmetry plane A-A for $\mathrm{A}=0.5 \mathrm{~m}$.

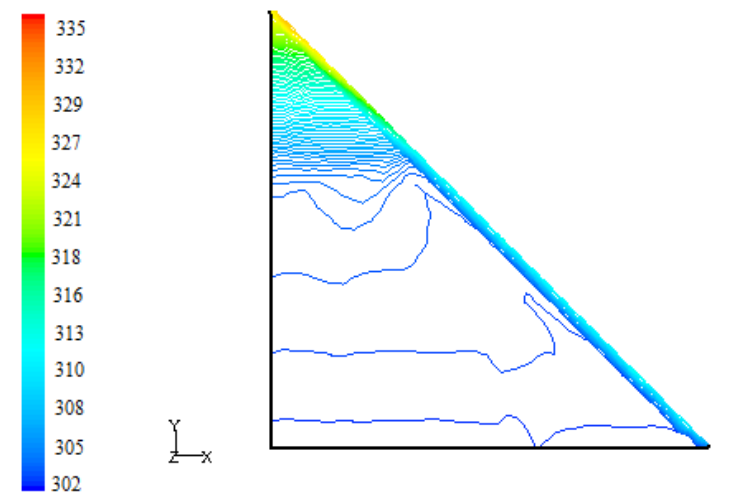

(b) Isothermal temperature lines at symmetry plane $A-A$ for $A=1 \mathrm{~m}$.

Fig. 4. Storage water stratification inside the Triangular collector

The agreement between the numerical predictions and the experimental data is good up to 2 p.m. as shown from Fig.(5). Also, it is noted that a larger volume means the water capacity increases, and hence the storage water temperatures at the end of day decreases and vice versa. This is shown in Fig. 6. It is interesting to note that as the volume increases the collection efficiency increases as shown in Fig.7 because the thermal losses to the outside air decrease.

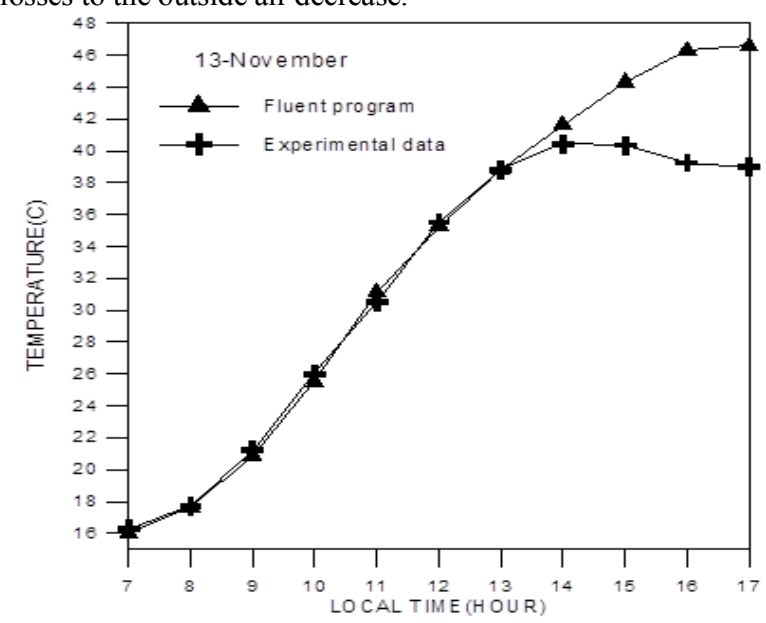

Fig. 5. Numerical and experimental variation of the mean storage temperature

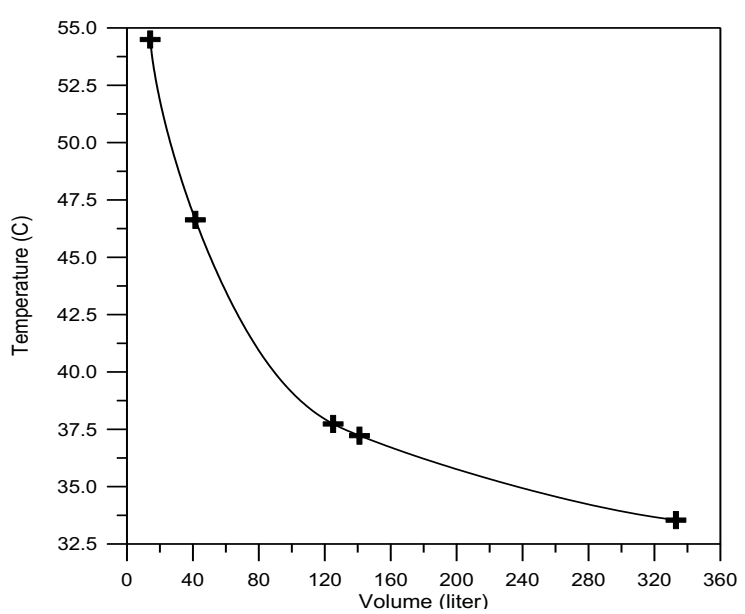

Fig. 6 . The relation between the mean storage temperature and the collector volume

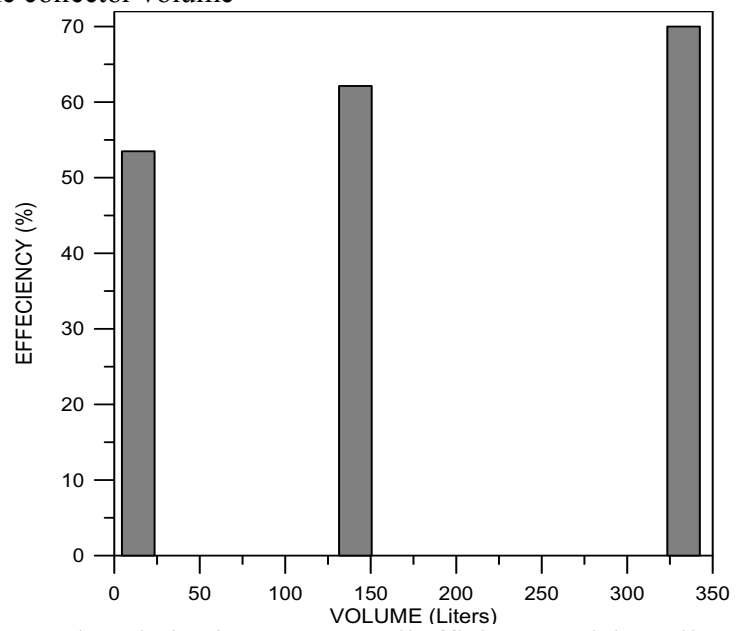

Fig.7. The relation between overall efficiency and the collector volume.

\subsection{Effect of the Internal Partition}

It was suggested to investigate the influence of using an internal partition inside the collector and study its influence on the temperature distribution and collector performance. This was done by using an internal partition with certain heights positioned in different locations as shown in Fig. (8) giving four different cases. All tests were carried out for a typical cold day.

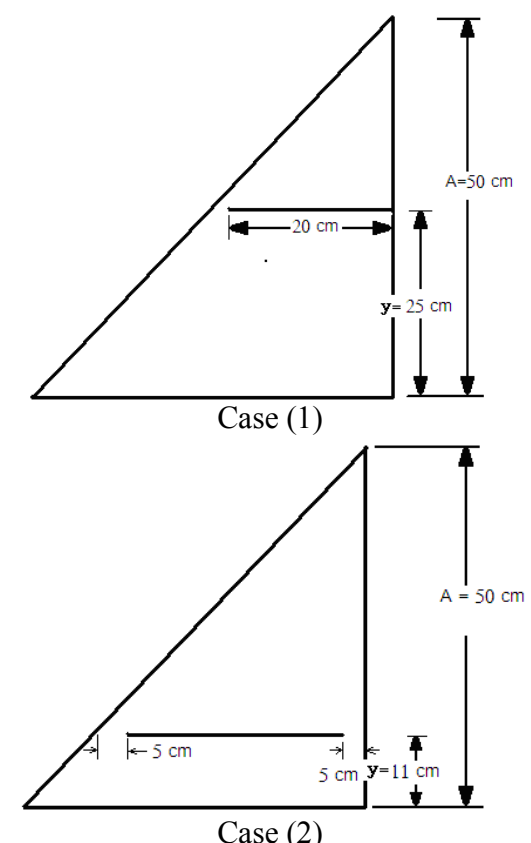



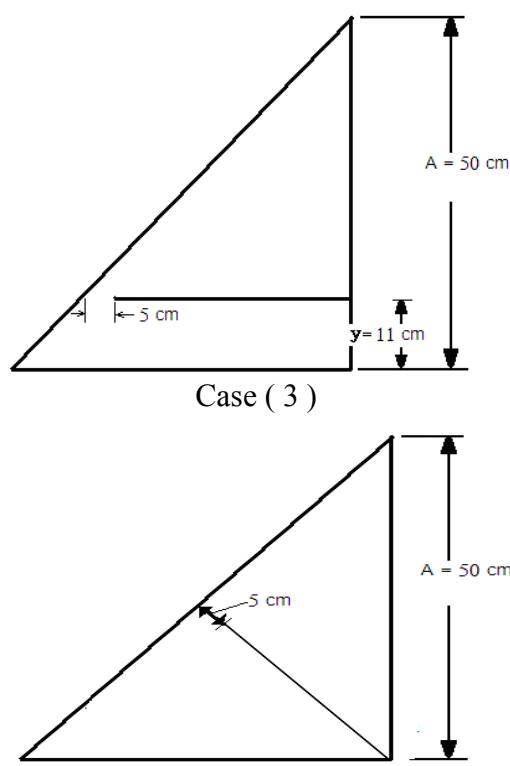

Case (4)

Fig. 8. shows the various locations of partitions

The mean storage temperature will be used as a criterion for assessment. It is observed that, when the partition is in a position which separates the collector into two equal volumes as in cases 2 and 3, there is no clear effect of the partition on the storage water temperature as shown in Fig. (9). The influence of the internal barrier is pronounced in cases 1 and 4, whereby an increase in the mean storage temperature is obtained. The separation between the hot and cold water causes this increase. It is noticed from Fig. (9) that the mean storage temperature for case (1) reaches $49^{\circ} \mathrm{C}$, which is higher than for other cases.

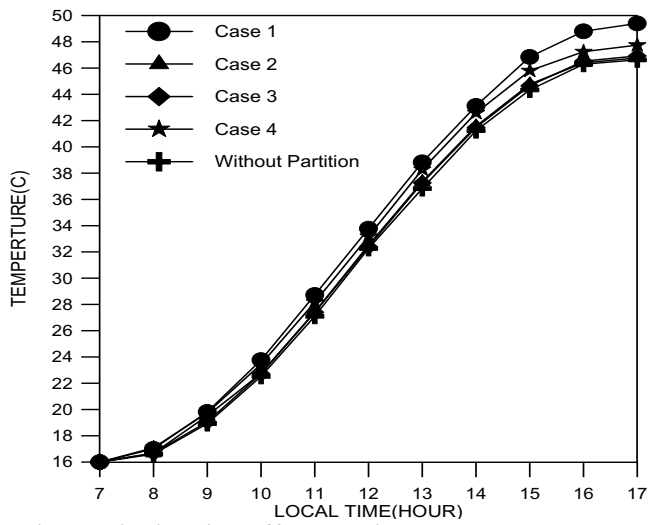

Fig. 9. shows the barrier effect on the mean storage temperature

Fig. (10) shows the effect of the barrier on the maximum temperature at the top of the collector. As shown, the maximum temperature was at 2 p.m. and reduced at the end of the operation period (Mozumder, 2013).

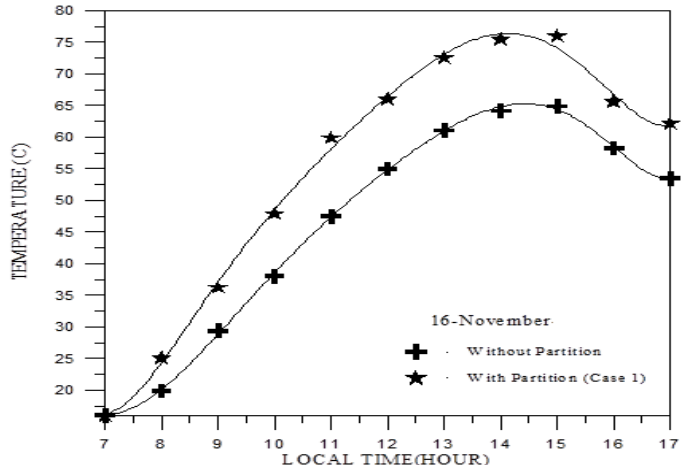

Fig. 10. Effect the effect of partition on the max temperature in case 1
Fig. (11) shows the temperature distribution of water in a triangular tank at 3 p.m. for a typical cold weather. The partition of the case (1) hinders direct circulation between warm and cold fluid, which is a useful result in positioning the cold- water inlet and the hot water outlet. Also, it shows that mainly at no load condition, the cold water is confined below the partition while the warm water is above the barrier. It is noticed that the temperature difference between the top and bottom of the collector increased significantly as compared with the no partition case. Also, the stratification in the collector was not disturbed by the existence of the adiabatic partition (Varghese \& Manjunath, 2017).
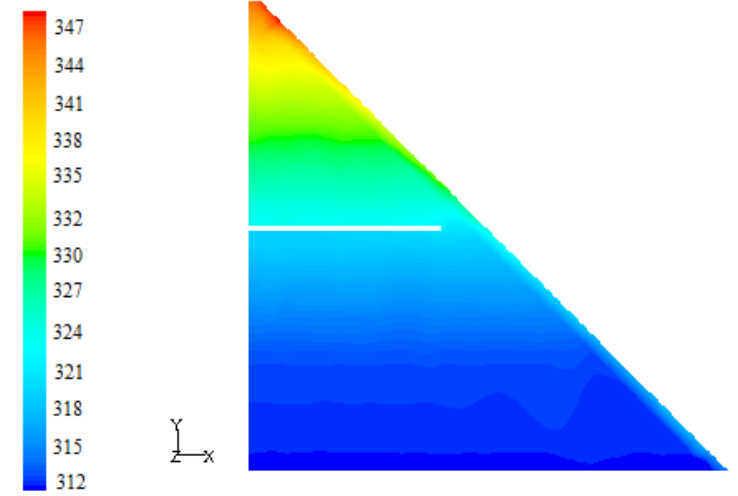

Fig.(11) shows the effect of partition on temperature distribution $(\mathrm{K})$ in a symmetry plane for case 1 .

Fig. (12) shows the flow of water inside the system at 2 p.m. for a typical winter day. The flow included three relatively distinct regions $(\mathrm{A}, \mathrm{B}$ and $\mathrm{C})$ as denoted on this figure. The flow in region $\mathrm{A}$ is laminar and moves along the inclined surface and then turns left to perform an anticlockwise circulation inside the collector at the base. The second and third regions, $\mathrm{B}$ and $\mathrm{C}$ are characterized by complex random motion. The presence of the partition hinders the particle motion from region $\mathrm{B}$ to $\mathrm{C}$ or vice versa.
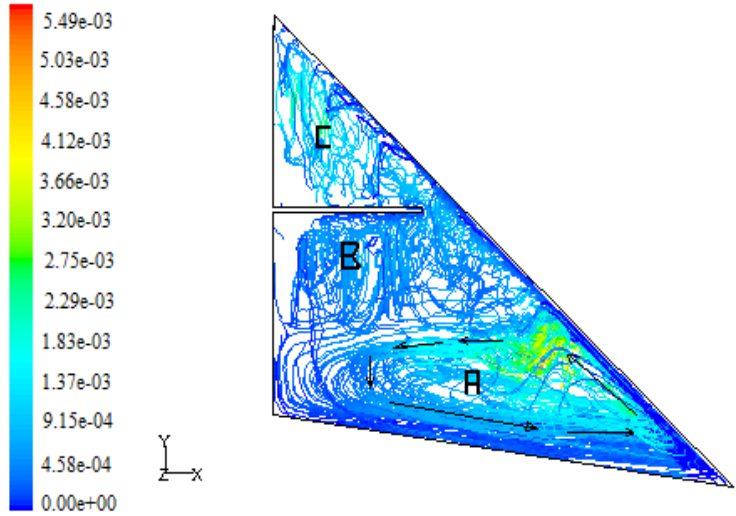

Fig. 12. shows the effect of partition on particle motion

\subsection{Effect of Nocturnal Cooling on Triangular Collector Performance}

The intimate contact between the storage fluid and the absorber plate in the storage collector facilitates efficient solar conversion but can also lead to substantial heat losses during periods of low and/or zero solar radiation particularly at night. Convective heat exchange with the ambient air and radiated heat transfer to the cold night sky are the significant mechanisms of heat losses. This effect can be reduced, to some extent, by covering the transparent face of the system by a removable insulating cover such as cork of $50 \mathrm{~mm}$ thickness. It can be removed early in the next day so that the water remains warm until the next morning. The dynamic response of the system during such cooling hours was analyzed by doing the transient study of the system and carrying out the following tests: 
1- Transient study without an insulating cover.

2- Transient study with an insulating cover.

In test 2, it was assumed that the collector was covered by insulation at 5 p.m. and it was removed next day at about 7 a.m. During test 1, it was assumed that the front face was without any cover. Fig. 13 shows the performance of the system with and without insulating cover for different volumes of the triangular collector. Water temperature rises up to $46.6,37.25$ and $33.5^{\circ} \mathrm{C}$ respectively for 41,141 and 333 liters, at about 5 p.m. in the afternoon. This temperature falls to $34.8,32.9$ and $30.6^{\circ} \mathrm{C}$ in the next morning when these systems are left uncovered during nighttime (Ahmed \& Tahseen, 2008)

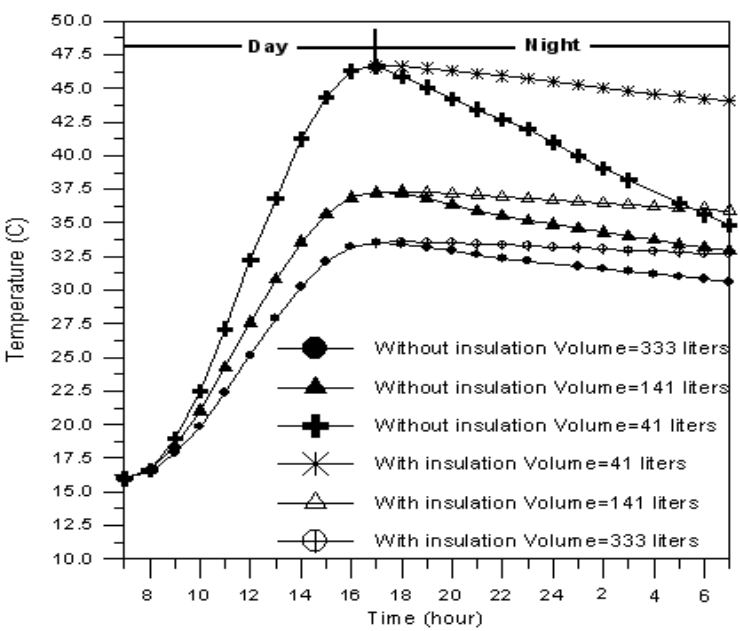

Fig. 11. shows the effect of insulating transparent cover during the off period on mean storage temperature

But when this collector is covered with insulation of $5 \mathrm{~mm}$ thickness, the water temperature falls to $44.1,35.9$ and $32.67{ }^{\circ} \mathrm{C}$ respectively as in table I. It means that the fall in water temperatures which were $11.83,4.32$ and $2.9{ }^{\circ} \mathrm{C}$ have been reduced to $2.55,1.3$ and $0.87^{\circ} \mathrm{C}$, respectively. The reduction in heat losses is a function of the volume of the collector. Since the decrease of water temperature is small in the case have 141 and 333 liters volumes of the collector, then the use of insulation cover is not very promising (Chabane, 2014; Michael \& Goic, 2015).

Most Iraqi houses contain a storage tank situated over the roof of the house for storing the water. The current system can also be used for storing water (Ahmed, 2016). During summer, the water temperature rises up to levels that prevent use of this water for drinking and other house purposes. An experiment has been conducted to determine average temperature rise for the collector for the $14^{\text {th }}$ of June. The tank was filled at $6 \mathrm{a} . \mathrm{m}$. and the transparent face was covered throughout the day. The mean storage temperature rose from $26{ }^{\circ} \mathrm{C}$ to $31{ }^{\circ} \mathrm{C}$. Thus, using this system could considerably reduce the energy required to reduce water temperature in house cooler (Ahmed, 2018).

Table 1. Effect of nocturnal cooling on mean storage temperature in the next morning

\begin{tabular}{|c|c|c|}
\hline $\begin{array}{c}\text { Collector } \\
\text { volume } \\
\text { (liters) }\end{array}$ & \multicolumn{2}{|c|}{ MEAN STORAGE TEMPERATURE $\left({ }^{\circ} \mathbf{C}\right.$ ) } \\
\cline { 2 - 3 } & Without cover $\boldsymbol{~}^{\circ}$ C) & With cover $\left({ }^{\boldsymbol{}}\right.$ C) \\
\hline 41 & 34.8 & 44.1 \\
\hline 141 & 32.9 & 35.9 \\
\hline 333 & 30.6 & 32.67 \\
\hline
\end{tabular}

\section{CONCLUSIONS}

From the obtained results, we can conclude the following notes can be observed:

1. The presence of a horizontal barrier inside the triangular storage collector increases stratification of water and renders a higher mean storage temperature. The enhancement was best at $\mathrm{y}=0.5 \mathrm{~m}$. The mean storage temperature for case (1) reaches $49 \mathrm{oC}$, which is higher than for other cases.

2. Stratification behavior diminishes with increasing volume because the turbulent effect begins to appear.

3. Covering the sunlit area of the system with insulation during night time improves the performance. Water temperature rises up to $46.6,37.25$ and $33.5^{\circ} \mathrm{C}$ respectively for 41,141 and 333 liters, at about 5 p.m. in the afternoon. This temperature falls to $34.8,32.9$ and $30.6{ }^{\circ} \mathrm{C}$ in the next morning when these systems are left uncovered during nighttime

\section{REFERENCES}

A. A. Adeyanju, "Economic Analaysis of Combined Packed Bed Energy Storage and Solar Collector System,” Int J Renew ENERGY Res, vol. 3, no. 4, 2013.

A. Mozumder, "An Integrated Collector Storage Solar Water Heater and Study of its Temperature Stratification," Open J Appl Sci, vol. 03, no. 01, pp. 112-115, 2013.

F. Mohammed, O. Khalil, and A. Emad, "Effect of climate and design parameters on the temperature distribution of a room,” J Build Eng, vol. 17, no. February, pp. 115$124,2018$.

H. K. V. and W. Malalasekera, Introduction to Computational Fluid Dynamics, 2nd ed. Harlow, 2007.

I. ANSYS, ANSYS Fluent Tutorial Guide, vol. Releas 15., no. 1. Canonsburg, 2013.

J. J. Michael, I. S, and R. Goic, "Flat plate solar photovoltaicthermal (PV/T) systems: A reference guide," Renew Sustain Energy Rev, vol. 51, pp. 62-88, 2015.

J. Varghese and K. Manjunath, "Experimental investigation and comparison between an integrated compound parabolic domestic solar water heater with and without an air gap introduced at the arms of the CPC," Int J Adv Res Innov, vol. 5, no. 1, pp. 90-93, 2017.

K. A. Joudi, I. A. Hussein, and A. A. Farhan, "Computational model for a prism shaped storage solar collector with a right triangular cross section," Energy Convers Manag, vol. 45, no. 3, pp. 391-409, 2004.

K. ahmed Joudi, "Storage solar collector," 2255, 1990

M. A. Al-nimr, I. A. Al-darawsheh, and L. A. Al-khalayleh, "A novel hybrid cavity solar thermal collector," Renew Energy, vol. 115, pp. 299-307, 2018.

M. Chaabane, H. Mhiri, and P. Bournot, "Thermal performance of an integrated collector storage solar water heater (ICSSWH) with phase change materials (PCM)," Energy Convers Manag, vol. 78, pp. 897-903, 2014.

M. M. Rahman, M. M. Billah, N. . Rahim, N. Amin, R. Saidur, and M. Hasanuzzaman, "A numerical model for the simulation of double-diffusive natural convection in a triangular solar collector,” Int J Renew Energy Res, vol. 1, pp. 50-54, Jun. 2011.

O. K. Ahmed and A. H. Ahmed, Principles of Renewable energies, First edit. Baghdad: Foundation of technical education, 2011.

O. K. Ahmed and S. M. Bawa, "Reflective mirrors effect on the performance of the hybrid PV/thermal water collector," Energy Sustain Dev, vol. 43, pp. 235-246, 2018.

O. K. AHMED and S. M. BAWA, "THE COMBINED EFFECT OF NANOFLUID AND REFLECTIVE MIRRORS ON THE PERFORMANCE OF PV/THERMAL SOLAR COLLECTOR," Therm Sci, pp. 1-16, 2018.

O. K. Ahmed and T. A. Tahseen, "Studying the optimal performance of a storage solar collector for Iraqi environment," in First scientific conference Technical college of Najaf, 2008, pp. 129-144. 
O. K. Ahmed and Z. A. Mohammed, "Dust effect on the performance of the hybrid PV/Thermal collector," Therm Sci Eng Prog, vol. 3, pp. 114-122, Feb. 2017.

O. K. Ahmed, "A numerical and experimental investigation for a triangular storage collector," Sol Energy, vol. 171, no. June, pp. 884-892, 2018.

O. K. Ahmed, "Assessment of the Performance for a New Design of Storage Solar Collector," Int J Renew energy Res, vol. 8, no. 1, pp. 250-257, 2018.

O. K. Ahmed, "Effect of Dust on the Performance of Solar Water Collectors in Iraq," Int J Renew Energy Dev, vol. 5, no. 1, pp. 65-72, 2016.

O. Khalil Ahmed and Z. Aziz Mohammed, "Influence of porous media on the performance of hybrid PV/Thermal collector," Renew Energy, vol. 112, pp. 378-387, 2017.

O. Khalil Ahmed, "Experimental and numerical investigation of cylindrical storage collector (case study)," Case Stud Therm Eng, vol. 10, pp. 362-369, 2017.

R. Ben Slama, "Experimentation of a Plane Solar Integrated Collector Storage Water Heater," Energy Power Eng, vol. 4, pp. 67-76, 2012.

R. Shukla, K. Sumathy, P. Erickson, and J. Gong, "Recent advances in the solar water heating systems: A review," Renew Sustain Energy Rev, vol. 19, pp. 173-190, 2013. 